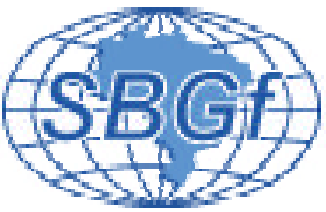

\title{
Cunhas de Refletores Mergulhantes no Embasamento da Margem Continental Equatorial Brasileira e Bacia Oceânica Adjacente.
}

\author{
Lilian Évile Mansur de Souza ${ }^{\text {; }}$ Sidney Luiz de Matos Mello ${ }^{1}$ Cleverson Guizan Silva ${ }^{1 .}$ \\ ${ }^{1}$ Laboratório de Geologia Marinha LAGEMAR, Universidade Federal Fluminense, RJ, Brasil (e-mail: evile@igeo.uff.br)
}

Copyright 2006, SBGf - Sociedade Brasileira de Geofísica

Este texto foi preparado para a apresentação no II Simpósio de Geofísica da Sociedade Brasileira de Geofísica, Natal, 21-23 de setembro de 2006. Seu conteúdo foi revisado pela Comissão Tecno-científica do li SR-SBGf mas não necessariamente representa a opinião da SBGf ou de seus associados. E proibida a reproducão total ou parcial deste material para propósitos comerciais sem prévia autorização da SBGf.

\section{Resumo}

O presente estudo investiga a ocorrência de cunhas de refletores mergulhantes no Embasamento da margem equatorial brasileira e bacia oceânica adjacente, a partir da interpretação de perfis sísmicos de reflexão multicanal obtidos pelo Projeto LEPLAC (LEVANTAMENTO DA PLATAFORMA CONTINENTAL BRASILEIRA). Refletores mergulhantes para o oceano e para o continente, com baixo ângulo e conformidade côncava ou convexa, ocorrem em crosta oceânica próximo a Cadeia Norte Brasileira e Elevação do Ceará. A natureza destes refletores na porção superior e média da crosta oceânica parece relacionada a vulcanismo oceânico em centros de expansão pretéritos ou a vulcanismo anômalo associado à Cadeia Norte-Brasileira e à Elevação do Ceará. Estes refletores, portanto, embora semelhantes àqueles no embasamento continental e transicional na margem continental sul-sudeste brasileira, não podem ser interpretados como Seaward Dipping Reflectors, cuja natureza está ligada ao processo de abertura do oceano Atlântico Sul em margem vulcânica.

\section{Introdução}

A margem continental brasileira é tectonicamente compartimentada (MOHRIAK, 2001), sendo a margem continental equatorial transformante, a margem leste divergente, com baixa atividade vulcânica pré-abertura e a margem sul-sudeste divergente com intensa atividade vulcânica, desde do derrame de basaltos Serra Geral (127 Ma) até a formação da Elevação do Rio Grande (80 Ma).

A Margem Equatorial Brasileira é caracterizada por estreitos centros de expansão deslocados por falhas transformantes, com a presença de lineamentos de intrusões vulcânicas (MOHRIAK, 2001; SZATMARI et. al., 1987). É caracterizada também por eventos vulcânicos relacionados ao centro de expansão mesoceânico, bem como pelo vulcanismo anômalo associado à Cadeia Norte-Brasileira e à Elevação do Ceará. Nota-se também a presença de lineamentos de intrusões vulcânicas relacionadas à Cadeia Fernando de Noronha e às zonas de fratura de Romanche e São Paulo. Ao longo destes lineamentos ocorrem vários montes submarinos ou afloramentos sob forma de ilhas vulcânicas (SICHEL et al. 2000).

Em geral, a formação das bacias marginais brasileiras normalmente está associada a complexos vulcânicos relacionados à ruptura do Gondwana. Muito destes complexos ocorrem sob forma de cunhas vulcanosedimentares de refletores mergulhantes para o mar (Seaward Dipping Reflector - SDRs) que foram imageados por levantamentos sísmicos tanto na margem continental brasileira quanto na margem africana (HINZ, 1981; MUTTER, 1985; GLADCZENKO et al. 1997).

Em particular, na margem continental brasileira as ocorrência de cunhas de refletores mergulhantes do tipo SDRs têm sido descritas, principalmente, ao longo da Margem Continental Sul-Sudeste Brasileira como parte da evolução de uma margem vulcânica (BASSETTO et al., 2000). O presente estudo revela também a ocorrência de refletores mergulhantes na margem equatorial brasileira e bacia oceânica adjacente. Para esta interpretação foram utilizados dados de reflexão sísmica multicanal obtidos pelo Projeto LEPLAC (LEVANTAMENTO DA PLATAFORMA CONTINENTAL BRASILEIRA).

\section{Dados e Metodologia}

Foram interpretadas 30 linhas sísmicas na margem continental equatorial brasileira e bacia oceânica adjacente, sendo 20 linhas transversais e 10 linhas paralelas a linha de costa. A orientação preferencial das linhas é sudoeste-nordeste. Estas linhas, correspondentes ao levantamentos Leplac VI, VIIIA, V e III foram sobrepostas a mapa de batimetria derivado de altimetria de satélite, mostrando o limite de crosta continental-oceânica proposto por RANGEL (n.d.) (Figura 1). A interpretação das linhas enfocou a caracterização de refletores mergulhantes no embasamento continental e oceânico, bem como a 
provável localização do limite crustal com base na assinatura sísmica do embasamento oceânico.

\section{Interpretação do Dados}

A Figura 1 apresenta as principais feições fisiográficas da margem continental equatorial e bacia oceânica adjacente. Estas feições são descritas por GORINI e CARVALHO (1984), destacando-se o Cone do Amazonas, o centro de expansão oceânica atual entre a placa sul-americana e a placa africana, localizado mais próximo da margem continental; as zonas de fraturas oceânicas, de direção leste-oeste; a Elevação do Ceará e a Cadeia Norte-Brasileira, formada por montes submarinos e guyots paralelos a linha de costa. Os perfis sísmicos interpretados se estendem desde a borda da platoforma continental até Elevação do Ceará, cobrindo, portanto, todo o Cone do Amazonas e a Cadeia NorteBrasileira em direção as zonas de fratura oceânicas.

A interpretação dos perfis sísmicos evidenciou um pacote sedimentar de espessura variável (entre 1 e 5,5 segundos em tempo duplo) sobre o embasamento continental e oceânico. Este pacote se apresenta planoparalelo ao fundo oceânico, porém, em alguns perfis se observa deformação sedimentar resultante de falhas, talvez relacionadas a reativação tectônica em zonas de fraturas.

A assinatura sísmica do embasamento é caracterizada por uma mudança abrupta no padrão da reflexão. $O$ embasamento oceânico apresenta refletores descontínuos e segmentados que marcam, claramente, o limite entre o pacote sedimentar e o topo do embasaemento oceânico, que trunca as reflexões caracteristicas do embasamento continental (Figura2).

A partir da assinatura sísmica do embasamento continental e oceânico foi inferido o limite crustal ao longo dos perfís transversais a margem continental, que por sua vez, foi correlacionável com o limite sugerido por RANGEL (n.d.), que envolveu também a análise de dados gravimétricos (Figura 1). As cunhas de refletores mergulhantes observadas em todos os perfis sísmicos ocorrem em crosta oceânica, não são contínuas numa mesma linha, mostrando intervalos entre uma sequência e outra. As cunhas podem ser muito ou pouco extensas, apresentando expessuras variáveis.

As linhas sísmicas do Leplac VI, localizadas mais ao norte, evidenciam a diminuição da espessura sedimentar em direção à bacia oceânica. A seqüência sedimentar mais espessa é da ordem de 5 segundos em tempo duplo (aproximadamente $4 \mathrm{Km}$ ). Das 11 linhas do Leplac VI, 10 transversais e 1 paralela à costa, foi notada a presença de cunhas de refletores mergulhantes em 10 delas (9 transversais e 1 paralela). A extensão desses refletores é variável de linha para linha, podendo alcançar até $91 \mathrm{Km}$ na linha 5010026 (Figura 3). Observa-se nesta linha sísmica a presença de dois altos vulcânicos no topo do embasamento, que podem estar relacionados a continuação lateral da Elevação do Ceará.

As linhas sísmicas do Leplac VIIIA também evidenciam uma diminuição na espessura sedimentar em direção à bacia oceânica com depocentro da ordem de 5,5 segundos em tempo duplo. As 10 linhas do Leplac VIIIA, 2 transversais e 8 paralela à costa, mostram a presença de cunhas de refletores mergulhantes em 2 linhas (1 transversais e 1 paralela). A maior extensão dos refletores mergulhantes alcança $30 \mathrm{Km}$ na linha 500536 (Figura 4), que corta transversalmente a Elevação do Ceará. Nesta linha, a porção sudoeste da Elevação do Ceará encontra-se coberta por sedimentos do Cone do Amazonas.

As linhas sísmicas do Leplac $V$ se estendem da plataforma continental até a zona de fratura de São Paulo. A interpretação destas linha foi dificil em função da qualidade dos dados. Nas 4 linhas do Leplac V, todas transversais, foram observadas cunhas de refletores mergulhantes em apenas uma, cuja extensão alcançou, aproximadamente, 30 km na linha 500507 (Figura 5).

Tal como as linha do Leplac V, as linha do Leplac III também apresentaram problemas de processamento. Das 5 linhas do Leplac III, 4 transversais e 1 paralela, foi notada a presenca de cunhas de refletores mergulhantes em apenas 1 delas, cuja extensão é da ordem de $5 \mathrm{Km}$ (Figura 6).

Em geral, as cunhas de refletores mergulhantes ocorreram predominantemente na camada superior da crosta, próximo ao topo do embasamento oceânico. No entanto, foram observadas cunhas de refletores mergulhantes em crosta mais profunda alcançando a profundidade de 2 a $4 \mathrm{Km}$ abaixo do topo do embasamento. A linha 500032 exemplifica refletores mergulhantes no embasamento oceânico em "crosta média" (Figura 7).

\section{Discussão e Conclusões}

A Margem Equatorial Brasileira corresponde a uma margem continental transformante que desloca estreitos centros de expansão mesoceânico, responsáveis por intenso vulcanismo e formação de nova crosta oceânica. Neste sentido, ocorre simultaneamente deslocamento lateral por meio das falhas transformantes e vulcanismo de origem extensional nos centros de expansão. A Cadeia Norte-Brasileira, parece resultar deste processo no qual a atividade vulcânica é controlada tectonicamente por falhas tranformantes (e.g., GORINI, 1981). Por sua vez, a Elevação do Ceará, com profundidade média atual de 3.100 metros, aparentemente resulta de atividade magmática, do tipo ponto-quente, localizado no centro de expansão a pelo menos $80 \mathrm{Ma}$. Neste caso, formando uma cadeia assímica em par com a Elevação de Serra Leoa (KUMAR, 1979).

Os refletores mergulhantes observados ao longo dos perfis sísmicos, apresentam-se com baixo ângulo e conformidade côncava ou convexa, ou até mesmo 
planos, localizados em crosta superior ou crosta média. Sua extensão lateral é variável e não são contínuos ao longo dos perfís. Ocorrer em direção ao mar (seaward), mas também em direção ao continente (landward), podendo num mesmo perfil apresentar, cunhas mergulhantes para o continente e para o oceano. $\mathrm{Na}$ linhas 501021 (Figura 8), podemos observar uma cunhas de refletores mergulhantes para o continente e para 0 oceano.

Essa variabilidade no estilo e na ocorrência de refletores mergulhantes na margem continental equatorial brasileira e bacia oceânica adjacente, não perimite fazer qualquer relação com as cunhas vulcano-sedimentares, que formam refletores mergulhantes para o mar (Seaward Dipping Reflectors - SDRs) em margens vulcânicas. Acredita-se, neste caso, que a maior parte dos refletores mergulhantes interpretados aqui tenha sua origem relacionada ao vulcanismo em centro de expansão normal e/ou ao intenso vulcanismo relacionado a formação da Elevação do Ceará e da Cadeia NorteBrasileira.

A ocorrência de refletores mergulhantes em crosta oceânica média parece compatível com o modelo de MORRIS et al. (1990), que sugere que as cunhas de refletores em "crosta-média" são formadas a partir de mecanismo extensionais associados a falhas normais em centro de expansão mesoceânico.

\section{Agradecimentos}

Lílian Évile Mansur de Souza é bolsista de mestrado do PRH-11/ANP do Depto. de Geologia-LAGEMAR/UFF, tendo sido incialmente bolsista da CAPES. Os dados sísmicos foram gentilmente cedidos pelo Projeto LEPLAC (DHN-Marinha do Brasil e Petrobras).

\section{Referências}

BASSETTO, M., ALKMIN, F.F., SZATMARI, P., MOHRIAK, W.U. (2000). The oceanic segment of the southern Brazilian margin: morpho-structural domains and their tectonic significance. In: Mohriak, W. U., Talwani, M. (eds.), Atlantic rifts and continental margins, AGU Geophysical Monograph 115:235-259.

ELLEN MORRIS, ROBERT S. WHITE, ROBERT $S$. DETRICK, JOHN C. MUTTER, PETER BUHL, TIMOTHY A. MINSHULL (1990). New seismic images of oceanic crustal structure: Geology, v. 18, p. 462-465.

GLADCZENKO, T. P., K. HINZ, ET AL. (1997). "South Atlantic volcanic margins." Journal of Geological Society 154: 465 - 470.

GORINI, M.A. 1981. The tectonic fabric of the equatorial Atlantic and adjoining continental margins. In: PETROBRAS. Estruturas etectonismo da margem continental brasileira, e suas implicações nosprocessos sedimentares e na avaliação do potencial de recursosminerais; relatório final. Rio de Janeiro, CENPES/DINTEP. p. 11-116 (Projeto REMAC 9)

GORINI, M.A. \& CARVALHO, J.C.(1984). Geologia da margem continental inferior brasileira e fundo oceânico adjacente,In: Schobbenhaus, C.; Campos,D.A.; Derze, G.R.; Asmus, H.E. (editores). Geologia do Brasil, coord.: Textoexplicativo do mapa geológico do Brasil e da área oceânica adjacente, incluindo depósitos minerais Escala 1:2500000 MME/DNPM, Brasília, p 473-489.

HINZ, K. (1981). A Hypothesis on Terrestrial Catastrophes: Wedges of Very Thick Oceanward Dipping Layers beneath Passive Continental Margins. Geologisches Jahrbuch, E(22):3-28.

KUMAR, N., (1979). Origin of paired aseismic rises: Ceará and Sierra LeoneRise in the Equatorial and the Rio Grande Rise and Walvis Ridge in theSouth Atlantic. Mar. Geol., 30:175-191.

MATOS, R.M.D. \& WAICK, R.N., 1998. A unique transform margin: the Equatorial Atlantic. Proceedings of the Rio'98 AAPG International Conference and Exhibition, pp. 798-799, Rio de Janeiro, Brazil.

MILANI, E.J., 1987. Aspectos da evolução tectônica das Bacias do Recôncavo e Tucano Sul, Bahia, Brasil. Petrobras, Série Ciência-Técnica-Petróleo 18, Rio de Janeiro, Brasil.

MILANI E. J., BRANDÃO J. A. S. L., ZALÁN P. V. \& GAMBOA L. (2000) A. P. Petróleo na margem continental brasileira: geologia, exploração, resultados e perspectivas. Rev. Bras. Geof. v.18n.3

MOHRIAK, W.U., PALAGI, P.R., \& MELLO, M.R. (1998). Tectonic evolution of South Atlantic salt basins. AAPG Bull., v. 82, p. 1945. AAPG International Conference and Exhibition, November 811, Rio de Janeiro, Abstract volume, p. 424-425.

MOHRIAK, W.U. (2001). Bacias Sedimentares da Margem Continental Brasileira (Cap.III). Geologia, Tectônica e Recursos Minerais do Brasil: L. A. Bizzi, C. Schobbenhaus, R. M. Vidotti e J. H. Gonçalves (eds.) CPRM, Brasília.

MUTTER, J.C. (1985). Seaward Dipping Reflectors and the Continent-Ocean Boundary at Passive Continental Margins, Tectonophysics, 114:117-131.

RANGEL, A. A. (n.d.). Brasil além das 200 milhas. Diretoria de hidrologia e Navegação(DNH). Assessoria para o projeto LEPLAC.

SICHEL, S.E., MAIA, M., ESPERANÇA, S. HEKINIAN, R., JUTEAU, T., CARNEIRO,L.M., ALVES. E.C. (2000). Synthesis on the Tectonics and Geochemistry of the St. Paul Transform Fault, Equatorial Atlantic. In: SBGf, International Congress of the Brazilian Geophysical Society, 7, Salvador, Anais, 1608-1611.

SZATMARI, P.; FRANÇOLIN, J. B. L.; ZANOTTO, O. \& WOLFF, S. (1987). Evolução tectônica da margem equatorial brasileira. Revista Brasileira de Geociências, 17 (2): 180-188. 

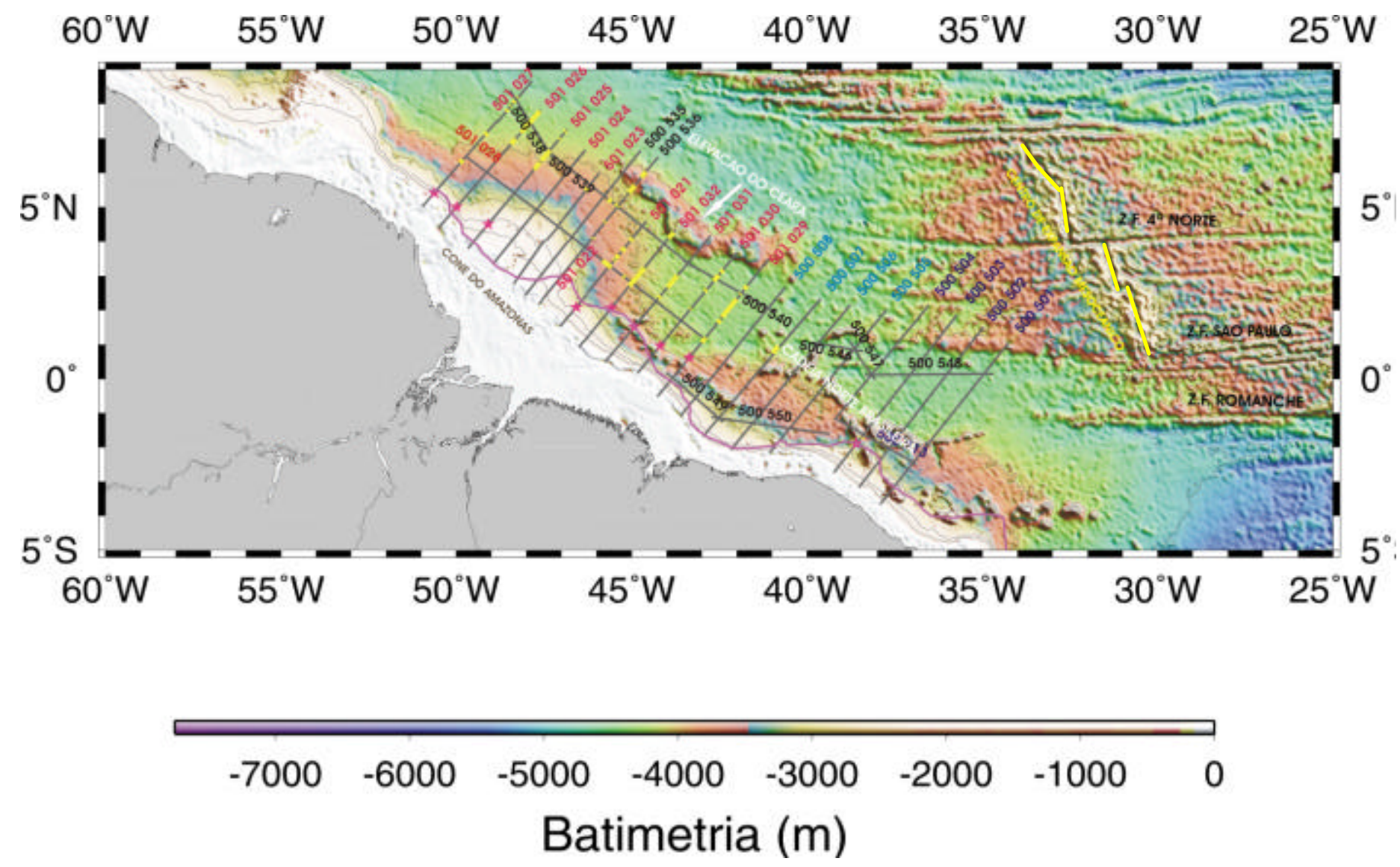

Figura 1: Mapa Batimétrico da Margem Equatorial com localização das linhas sísmicas do Projeto LEPLAC, cada qual indicada com uma numeração colorida referente a cada levantamento: Leplac VI - vermelho, Leplac VIIIA - preto, Leplac V - azul claro e Leplac III- azul escuro. Em amarelo está registrada a ocorrência de refletores mergulhantes ao longo de cada linha. O limite crustal de RANGEL (n.d) está marcado por uma linha rosa contínua, enquanto as estrelas rosas marcam o limite entre embasamento oceânico e continental com base na interpretação sísmica. O centro de expansão mesoceânico está representado através de uma linha amarela.

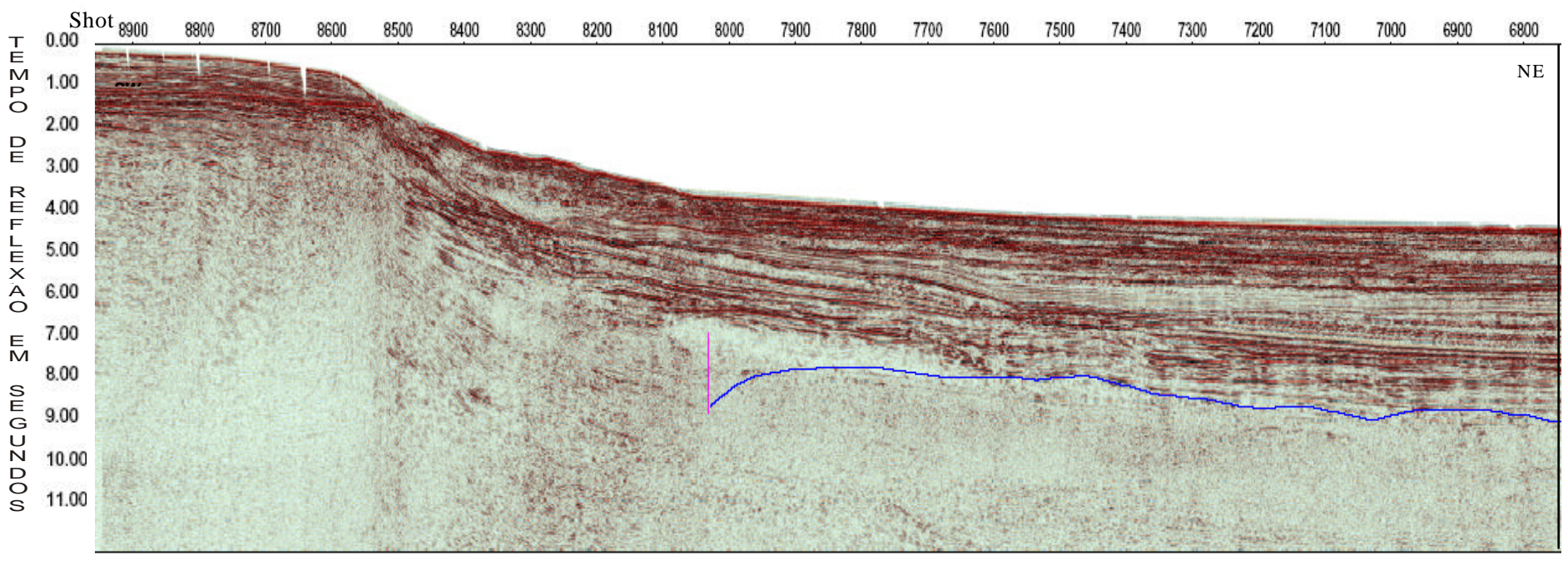

Figura 2: Trecho da Linha 501026 do Leplac VI, mostrando o truncamento das reflexões do embasamento oceânico com o embasamento continental. Topo do embasamento oceânico marcado na cor azul e início do embasamento continental marcado por uma linha rosa. Cada 100 pontos de tiro representa o intervalo de $5 \mathrm{Km}$ em escala real. 


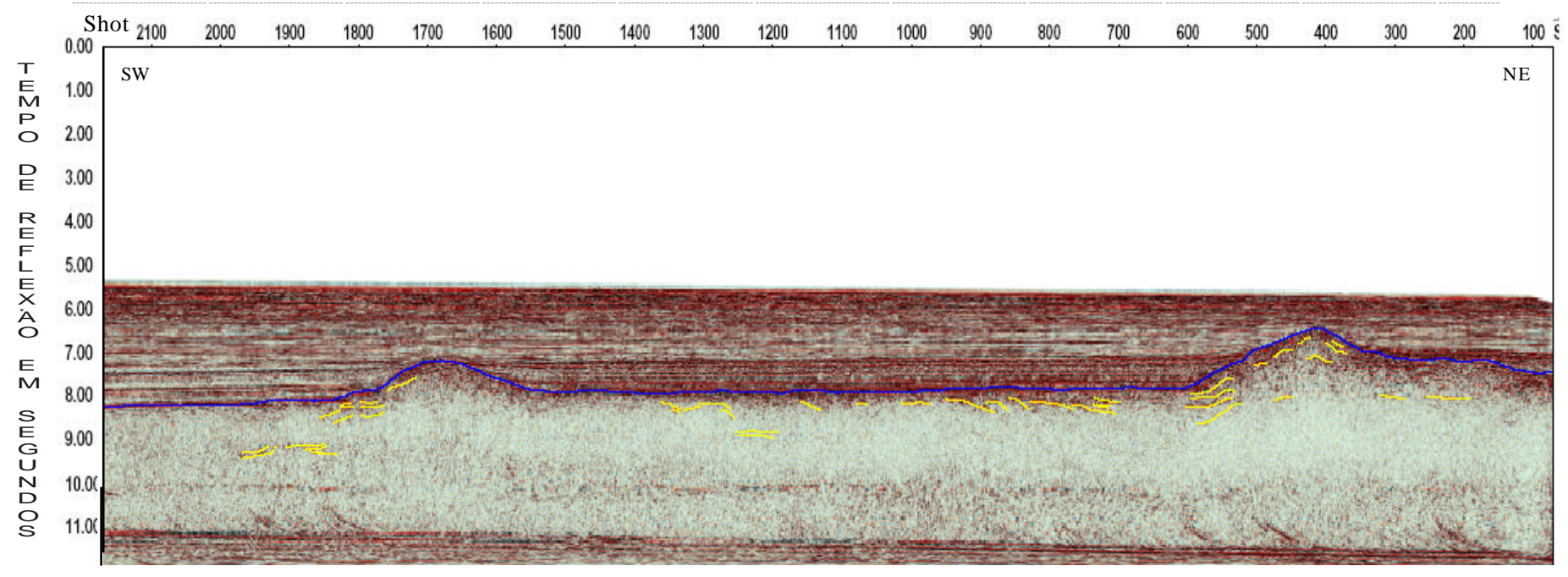

Figura 3: Trecho da Linha 501026 do Leplac VI, mostrando cunhas de refletores mergulhantes para o continente e para o oceano com até $91 \mathrm{Km}$ de extensão. Observa-se também a presença de dois altos vulcânicos que podem estar relacionados a extensão submersa da Elevação do Ceará para norte. Cada 100 pontos de tiro representa o intervalo de 5 $\mathrm{Km}$ em escala real.

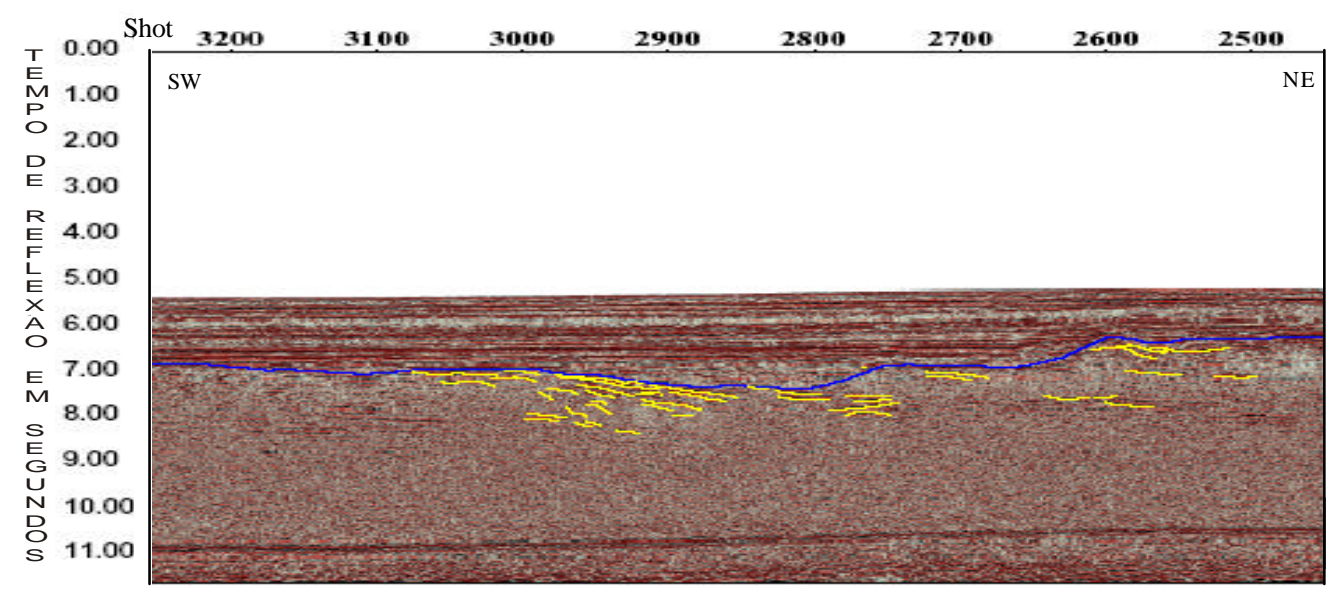

Figura 4: Trecho da Linha 500536 do Leplac V, mostrando cunhas de refletores mergulhantes de até 30 Km de extensão.

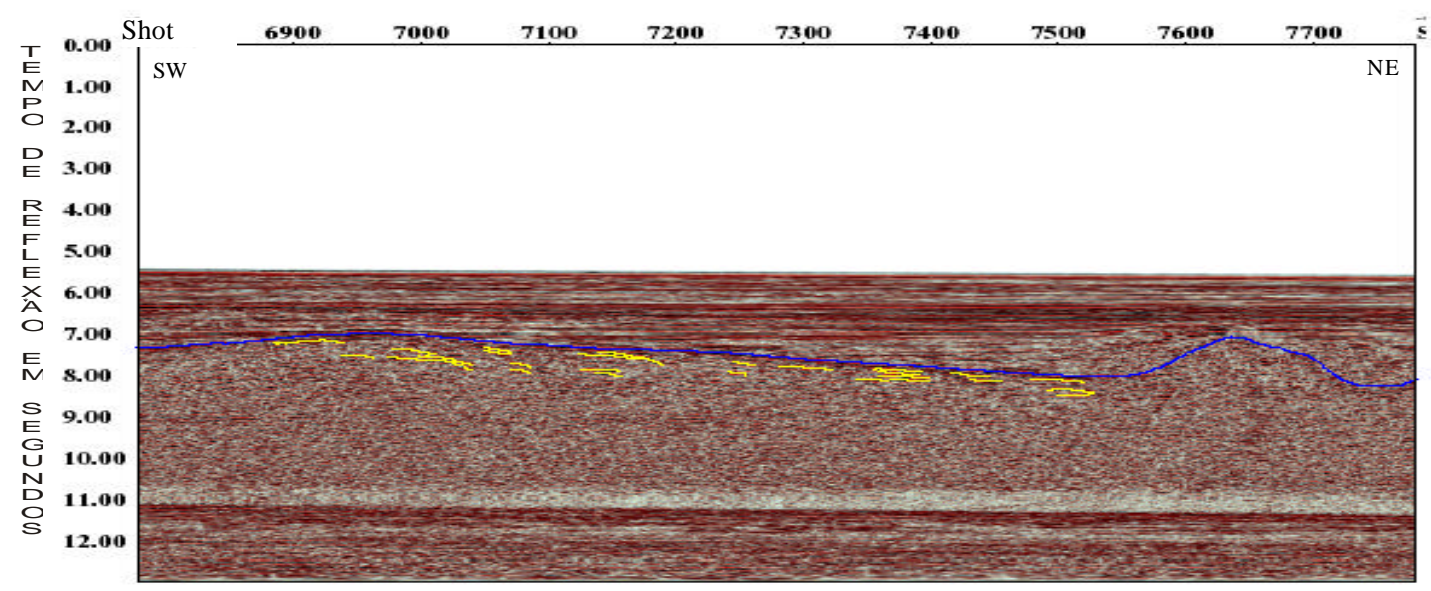

Figura 5: Trecho da Linha 500507 do Leplac V, mostrando cunhas de refletores mergulhantes alcançando $30 \mathrm{Km}$. 


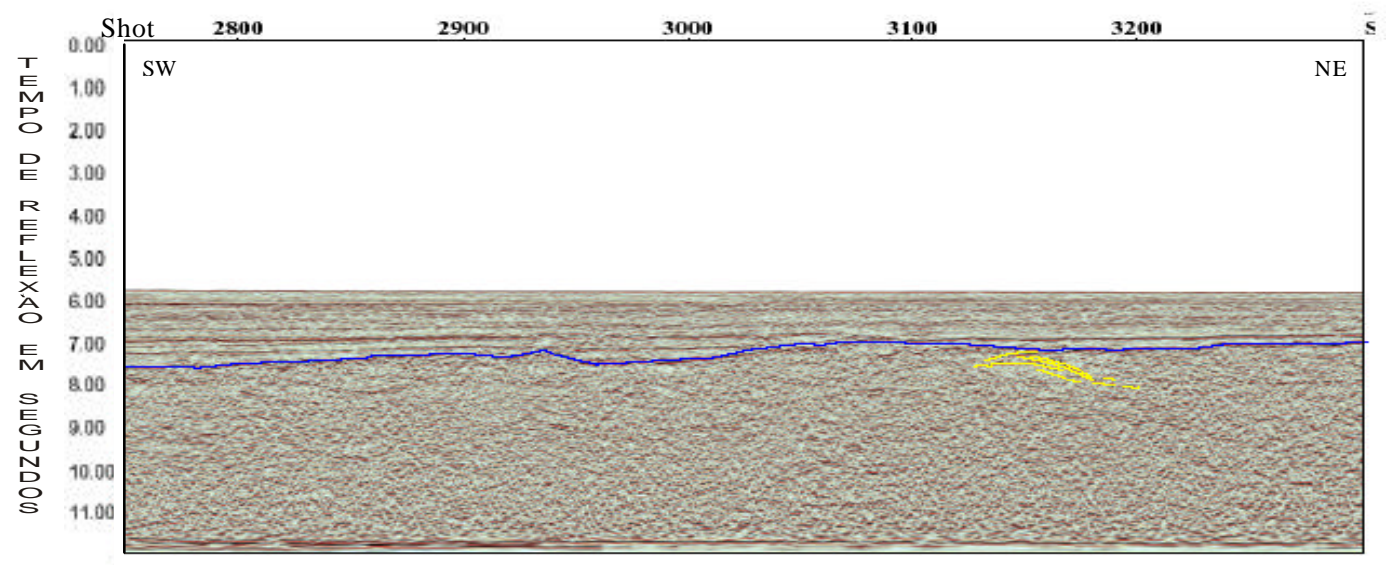

Figura 6: Trecho da Linha 500503 do Leplac V, mostrando cunhas de refletores mergulhantes de $5 \mathrm{Km}$.

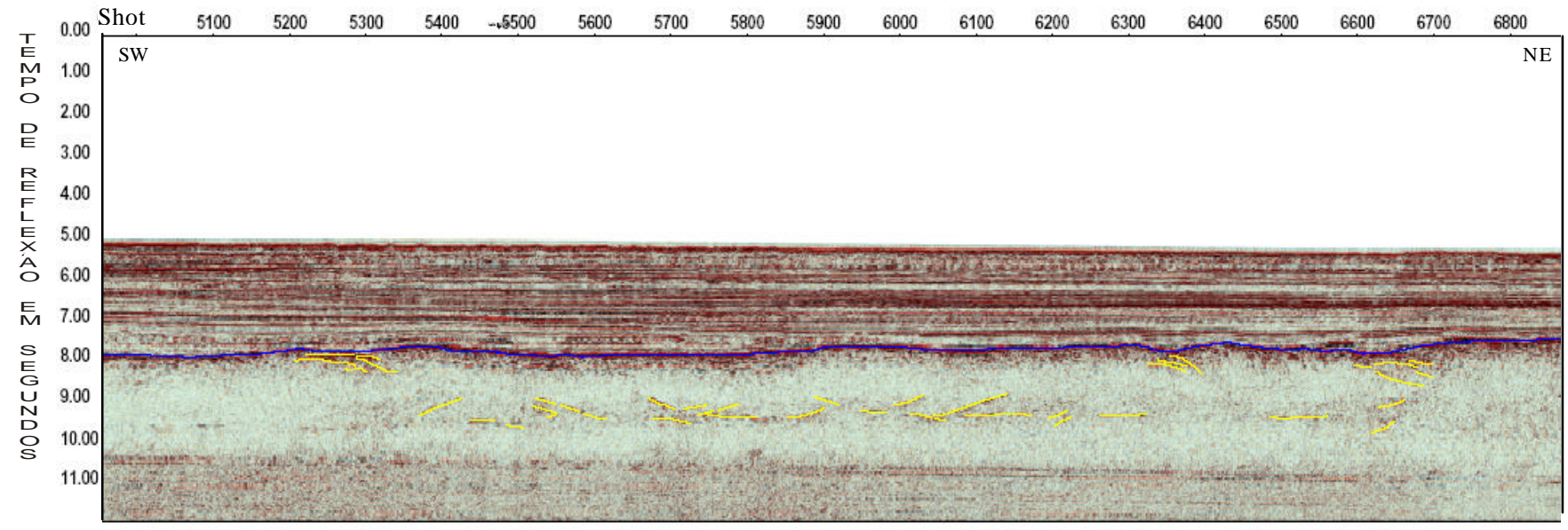

Figura 7: Trecho da Linha 500032 do Leplac VI, mostrando cunhas de refletores mergulhantes em "crosta média".

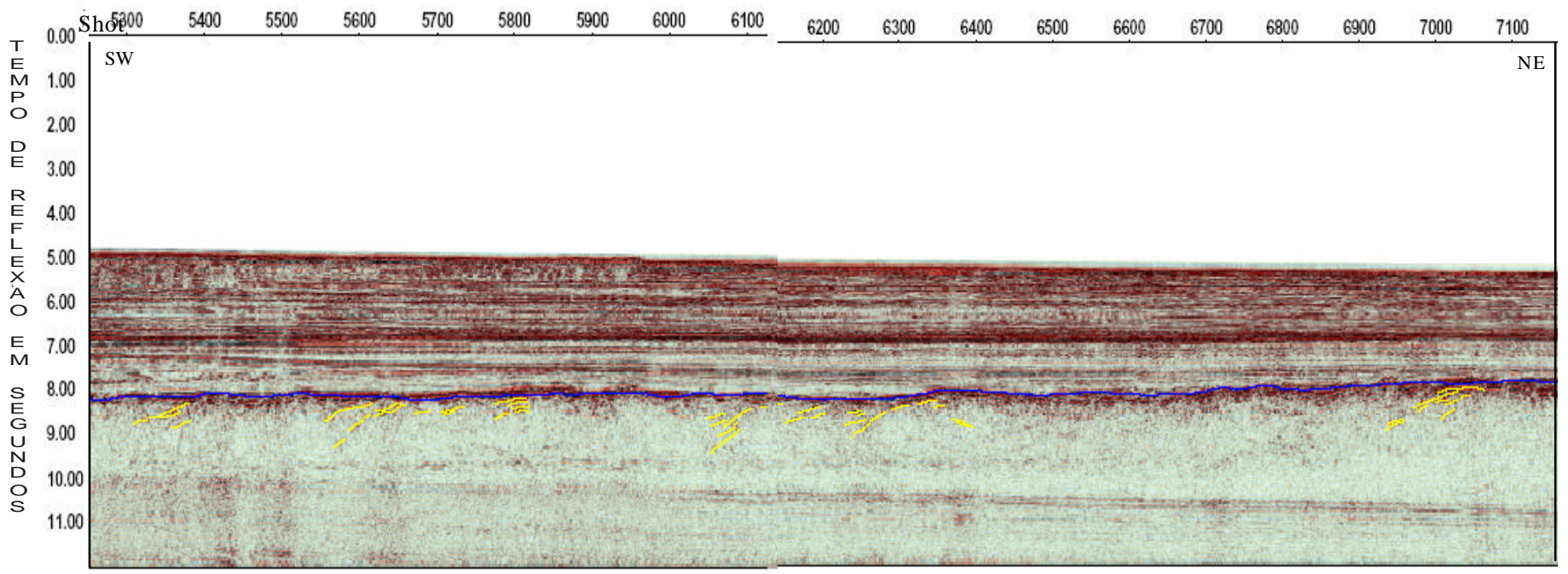

Figura 8: Trecho da linha 501021 mostrando cunhas de refletores mergulhantes para o continente. 